\title{
As Representações Sociais de aprendizagem compartilhadas por professores da rede privada: estudo comparativo
}

\author{
Teachers' Social Representations of Learning Shared \\ by Private School: a Comparative Study
}

Ana Amábile Gabrielle Rodrigues Leite ${ }^{1}$

(1) https://orcid.org/0000-0003-1157-5312

Ludgleydson Fernandes de Araújo²

(D) https://orcid.org/0000-0003-4486-7565

Fauston Negreiros
(D) $_{\text {https://orcid.org/0000-0003-2046-8463 }}$

1,2,3 Programa de Pós-Graduação em Psicologia, Universidade Federal do Delta do Parnaíba, Brasil

Resumo. Objetivo. Buscou-se apreender as representações sociais de professores da rede de ensino privada sobre aprendizagem no cenário tecnológico atual. Método. Participaram do estudo 40 professores, 20 que possuíam a tecnologia robótica educacional inserida na grade curricular de sua escola e 20 que não possuíam. Para coleta de dados utilizou-se questionário sociodemográfico, TALP e entrevista semiestruturada. Os dados coletados foram analisados através da técnica das redes semânticas e análise de conteúdo temática de Bardin. Resultados. Os professores que possuíam robótica educacional em sua grade curricular vincularam a aprendizagem enquanto construção do conhecimento baseada em uma abordagem construcionista. Enquanto os professores que não possuíam elucidaram a aprendizagem com uma visão instrucionista voltada para transmissão do saber que se dá pela busca.

Palavras-chave. Representações sociais, aprendizagem, professores.

Abstract. Objective. The aim was to understand private school teachers' social representations of learning in the current technological landscape. Method. Forty teachers participated in the study; twenty of whom had Educational Robotic Technology embedded in their school curriculum; and twenty of whom did not. Data collection was carried out via a socio-demographic questionnaire, TALP and semi-structured interviews. The data were analyzed using Bardin's technique of semantic networks and thematic content analysis. Results. Teachers with educational robotics in their curriculum-linked learning showed the construction of knowledge associated with a constructionist approach. Those who did not, conversely, elucidated learning with an instructional vision aimed at transmitting the knowledge that occurs through the search.

Keywords. Social representations, learning, teachers.

${ }^{1}$ Ana Amábile Gabrielle Rodrigues Leite. Programa de Pós-Graduação em Psicologia, Universidade Federal do Delta do ParnaíbaUFDPar, Brasil. Direção postal: Av. São Sebastião, 2819 Cidade Universitária 64202020 - Parnaíba, PI - Brasil.

E-mail: anamabilegabrielle@gmail.com

'Ludgleydson Fernandes de Araújo. Programa de Pós-Graduação em Psicologia, Universidade Federal do Delta do ParnaíbaUFDPar, Brasil. E-mail: ludgleydson@yahoo.com

${ }^{3}$ Fauston Negreiros. Programa de Pós-Graduação em Psicologia, Universidade Federal do Delta do Parnaíba-UFDPar, Brasil. E-mail: faustonnegreiros@ufpi.edu.br

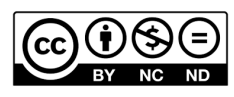




\section{Introdução}

O mundo contemporâneo passa por transformações significativas provocadas pela presença das novas tecnologias provenientes da automação e internet como, também, a ampla utilização de plataformas de aprendizagem virtuais on-line, protótipos robóticos na educação e dispositivos eletrônicos que facilitam a vida em sociedade. A explosão tecnológica permitiu o avanço de inúmeras áreas, modificando o comportamento e as relações sociais. Algumas dessas mudanças são percebidas nos espaços escolares, os quais não conseguiram, na mesma velocidade, modelar-se ao estudante do cenário tecnológico atual (Scheller et al., 2014).

A educação tende a ser entendida como um processo modificado historicamente, transformando-se com as inovações e tendências (Mel et al., 2015) e considerada, pelo poder político, como uma das responsáveis pela inserção das novas tecnologias na sociedade (Cruz, 2008). Constantemente, no atual contexto, profissionais deparam-se com novas exigências sociais que impõe questionamentos sobre o papel do professor no espaço escolar. Essas questões convidam aos professores a participar, problematizar e responder aos desafios educacionais, colocados por tais transformações (Cruz, 2008; Silva \& Lima, 2013; Silva et al., 2016).

Os Parâmetros Curriculares Nacionais de 1998 instituem que o desenvolvimento das tecnologias educacionais permite que a aprendizagem ocorra em diferentes lugares e meios. Ressalta a escola como lugar que contribui para a formação de indivíduos ativos e agentes criadores, pois o domínio da tecnologia só faz sentido, enquanto parte do contexto das relações entre homem e sociedade, representando formas de manutenção e de transformação das relações sociais, políticas e econômicas (Ministério da Educação e do Desporto \& Secretaria de Educação Fundamental [MEC \& SEF], 1998). E esse papel da escola prevê o abandono da ideia de que educar é apenas transmitir conhecimento (Verdum, 2013). No cenário tecnológico atual, estudos orientam a necessidade de refletir sobre os objetivos e a função social da instituição escola, enquanto local de aprendizagem que veja nas formas de comunicação e contextos de aprendizagem atuais, parceiros na criação de modelos de interação e construção colaborativa do conhecimento (Coutinho \& Lisbôa, 2011).

Uma vez que os processos de ensino e aprendizagem estão cercados pelo processo de globalização capitalista neoliberal que passa a exigir inovações aos professores (Castro, 2007), esta nova era, que oferta múltiplas possibilidades de aprender, torna o espaço físico da escola, tão proeminente em outras décadas, com este novo paradigma, em um local exclusivo para a construção do conhecimento e preparação do cidadão para a vida ativa (Coutinho \& Lisbôa, 2011).

É inegável o espaço que as novas tecnologias no contexto atual têm assumido. O professor, enquanto mediador no processo de ensino e aprendizagem, se depara hoje com esse universo tecnológico e precisa buscar formas de lidar com a nova realidade que se apresenta na sala de aula, buscando meios que motivem mais os seus alunos a aprenderem por meio de novas metodologias e orientá-los para que as informações advindas desse momento tecnológico se tornem significativas e contribuam para a construção do conhecimento (Silva et al., 2016). A tendência atual é que os professores se capacitem constantemente (Coutinho \& Lisbôa, 2011). 
Ao comparar o papel exercido pelo professor antes e após o advento das tecnologias educacionais, percebe-se que, como mediador de aprendizagem por meio de tecnologias, o professor deve agregar à sua experiência de vida profissional as proposições do mundo moderno (Silva \& Correa, 2014). A instrução que antes chegava ao aluno apenas pela fala do professor chega agora de diversas formas. Assim, a transmissão do saber, antes idealizada na figura do professor, exige que as novas propostas pedagógicas no século XXI estejam pautadas na pré-consciência de que a educação e seu contexto são um lugar de troca de conhecimentos, onde alunos e professores aprendem (Castro, 2007).

Estudos têm se concentrado em avaliar o uso de tecnologias na educação e as concepções e representações de professores sobre a utilização de computadores no processo de ensino (Chaib, 2003; Gregio, 2004; França \& Simon, 2013; Silva \& Lima, 2013), outros enfocam o desenvolvimento de avaliações sobre o impacto social de projetos educacionais baseados no uso das tecnologias (Vargas, 2003). Verifica-se que os professores acreditam no potencial das tecnologias para o processo de ensino e aprendizagem, no entanto, ao serem questionados sobre o quanto se sentem preparados, estes relatam pouco preparo para integrar as tecnologias nas aulas (Zambon et al., 2012).

Acredita-se que, além do conhecimento técnico para integrar tecnologias na rotina de uma sala de aula, é importante que o professor possua uma metodologia bem definida baseada em teorias da aprendizagem que apoiem o uso de tecnologias, pois a ausência de domínio metodológico restringe as possibilidades de uso dessas ferramentas pedagógicas no ambiente escolar, limitando-os a uma abordagem instrucionista do ensino baseada na teoria didática tecnicista sustentada pela teoria da aprendizagem comportamentalista (Silva et al., 2015) na qual as sequências de atividades de instrução são pré-definidas com ênfase na transmissão de conteúdos e na assimilação da informação (Gurgel et al., 2013).

Assim, o potencial da tecnologia enquanto aliada para construção do ensino só contribui efetivamente para a aprendizagem do aluno se o professor tiver uma formação de qualidade e se as informações forem transformadas em conhecimento a partir de reflexões e construções (França \& Simon, 2013). Nesse contexto, há necessidade de alinhamento entre a pedagogia, a didática do professor e o domínio da área tecnológica, pois essas práticas devem caminhar paralelamente no que diz respeito à aquisição desses conhecimentos (Gregio, 2004).

Um estudo realizado no Brasil sobre as representações sociais de professores do Ensino Fundamental, quanto ao uso de novas tecnologias no processo de aprendizagem, obteve argumentos de que a presença tecnológica atua como um reforço para a aprendizagem, além de facilitar na construção do conhecimento (Silva \& Lima, 2013; Moreira et al., 2014).

Além disso, estudos evidenciam que trazer as tecnologias para o ambiente educativo pode tornar o processo de ensino e aprendizagem mais prazeroso, chamativo e significativo para aquele que aprende e mais dinâmico para aquele que educa (Silva \& Correa, 2014). No entanto, a simples utilização dessa tecnologia não significa inovação pedagógica, pois exigiria uma metamorfose de todos os processos e atores envolvidos no ambiente de aprendizagem (Moreira et al., 2014).

Desta maneira, evidencia-se a necessidade de mudanças na forma de ensinar, em face às mudanças que vêm ocorrendo na sociedade e no mundo após a revolução tecnológica (Silva \& Silva, 2017). Uma vez que existe o advento dos hipertextos, os quais disponibilizam inúmeras informações em diferentes gêneros digitais, gerando novas formas de letramento 
(Silva et al., 2016), a tendência da gamificação como proposta pedagógica (Quinaud \& Baldessar, 2017) e a robótica educacional dentro do contexto escolar (Chitolina et al., 2016), há necessidade de verificar os recursos tecnológicos dispostos para transformá-los em conhecimentos (Silva et al., 2016).

Mediante necessidade de repensar a prática pedagógica do professor, visto que os alunos do cenário tecnológico atual crescem incorporando as inovações tecnológicas (Gregio, 2004), esse artigo buscou apreender as representações sociais dos professores sobre a aprendizegem que possuíam ou não a robótica educacional na grade curricular em seu contexto escolar.

A relevância deste estudo se encontra na possibilidade de acessar os elementos compartilhados pelos grupos de professores sobre o conceito de aprendizagem, tendo em vista que um grupo possui a robótica educacional em seu contexto e outro não, à luz da Teoria das Representações Sociais (TRS), utilizando a abordagem estrutural. Espera-se apreender as representações sociais desses professores, uma vez que os papéis que os sujeitos e grupos assumem diante da realidade interferem em suas práticas sociais (do Amaral \& Silva, 2013) e, consequentemente, em suas práticas pedagógicas no processo de ensino e aprendizagem.

\section{Método}

Trata-se de um estudo qualitativo descritivo com dados transversais e amostra não probabilística, por conveniência. A pesquisa foi realizada em duas escolas da rede de ensino privada na cidade de Parnaíba, no Estado do Piauí, com número populacional de 145.705 de acordo com o último censo realizado pelo Instituto Brasileiro de Geografia e Estatística (IBGE) em 2010. A escolha das escolas deu-se por suas semelhanças estruturais seguindo o critério de seleção de acordo com estudo prévio (Barros et al., 2006), no ano de 2018.

\section{Participantes}

Contou-se com a participação de 40 professores da rede de ensino privada. Utilizou-se, para delimitação do tamanho da amostra, o critério das redes semânticas (Vera-Noriega, 2005). A escolha de professores da rede privada justifica-se pela ausência de robótica educacional como metodologia disponível na grade curricular das escolas da rede pública em Parnaíba, Piauí. Após uma busca nas escolas privadas da cidade de Parnaíba, com a robótica educacional inserida na grade curricular, encontrou-se uma escola com 20 professores no corpo docente do fundamental. Em seguida, buscou-se uma escola que não possuísse robótica educacional em seu contexto para complementar a amostra.

Assim, a amostra foi composta por 20 participantes que possuíam a robótica educacional $(M=30,85$ anos; $D P=8,22)$ e 20 participantes não possuidores da robótica em seu contexto de ensino $(M=32,55$ anos; $D P=8,17)$ (Tabela 1).

Para participar da pesquisa, os professores deveriam ter como pré-requisito possuir experiência de prática em docência igual ou superior a seis meses, ministrar aula no ensino fundamental, e os participantes pertencentes ao grupo que não possui robótica não poderiam ministrar aula em escola que utilizasse da robótica inserida na grade curricular. Cabia ainda aos participantes dispor de livre escolha para participar ou não da presente pesquisa.

Actualidades en Psicología, 34(129), 2020, 33-45 
Tabela 1

Características sociodemográficas dos professores dos dois contextos educacionais

\begin{tabular}{lcc}
\hline & $\begin{array}{c}\text { Professores que possuíam } \\
\text { robótica educacional }\end{array}$ & $\begin{array}{c}\text { Professores que não possuíam } \\
\text { robótica educacional }\end{array}$ \\
\hline $\begin{array}{l}\text { Idade } \\
\text { Média }\end{array}$ & 30.85 & 32.55 \\
Gênero & & \\
$\quad$ Mulheres & $75 \%$ & $45 \%$ \\
Homens & $25 \%$ & $55 \%$ \\
Experiência em docência & & \\
6 meses a 1 ano & $40 \%$ & $15 \%$ \\
2 anos a 4 anos & $50 \%$ & $30 \%$ \\
4 anos ou mais & $10 \%$ & $55 \%$ \\
\hline
\end{tabular}

\section{Instrumentos}

Para realização da pesquisa utilizaram-se três instrumentos, sendo eles a Técnica de Associação Livre de Palavras (TALP), entrevista semiestruturada e questionário sociodemográfico.

Procedimento de coleta dos dados

Inicialmente, recorreu-se a autorização institucional de ambas as escolas para a aplicação da pesquisa com os professores, após aceitação via assinatura, a pesquisa foi enviada ao Comitê de Ética em Pesquisa da Universidade Federal do Piauí, retirado para avaliação cega, CAAE: 77363717.9 .0000 .5214 com o intuito de averiguar os parâmetros éticos regidos pela resolução de no 466/12 e seu aditivo 510/2016. Após liberação do projeto de pesquisa pelo Comitê de Ética por meio de parecer 2.308.987, por verificação de consonância com as normas éticas seguiu-se em direção as escolas para explicação dos objetivos da pesquisa frente ao público alvo. Na oportunidade, o Termo de Consentimento Livre e Esclarecido (TCLE) foi apresentado, lido e assinado pelos participantes voluntários. O primeiro instrumento aplicado foi o TALP, contendo como palavra-estímulo "Aprendizagem", e aos participantes orientou-se que escrevessem as cinco primeiras palavras que viessem à mente após a exposição da palavra-estímulo. Em seguida, foram instruídos a hierarquizar as palavras em ordem de importância, assinalando com o número 1 a palavra mais importante e com o número 5 a palavra menos importante. A entrevista semiestruturada foi, então, realizada. Nela, o participante foi convidado a discorrer sobre seus entendimentos sobre aprendizagem com a pergunta eliciada: "O que você entende por aprendizagem?".

O terceiro instrumento foi um questionário sociodemográfico que objetivou caracterizar a amostra colhida, abrangendo idade, gênero, aparelhos tecnológicos que possuía em casa - celular, computador, notebook, tablet, entre outros - e tempo de experiência de prática docente. A aplicação teve uma duração de 6 minutos para cada participante.

As abordagens ocorreram nos intervalos entre aulas ministradas em ambas as escolas. Durante as abordagens, justificou-se o objetivo da pesquisa, seu caráter sigiloso e 
anônimo, assim como também a apresentação do TCLE, seguido de assinatura para os que consentissem a participação voluntária. Dos 25 professores da escola que possuía robótica educacional, negaram-se a participar da pesquisa um total de 5 professores. Dentre os motivos para a recusa, enumera-se a dificuldade de tempo disponível para responder a pesquisa, insegurança quanto às finalidades dos relatos e desencontros. Da escola que não possuía robótica educacional, de um total de 23 professores, apenas 3 não participaram da pesquisa. A não participação, conforme a explicação dos professores, decorre da falta total de informação sobre o tema.

\section{Análise dos dados}

Os dados coletados no questionário sociodemográfico foram tratados através de análises estatísticas, a fim de obter informações para a caracterização da amostra. Os dados obtidos com o TALP foram transcritos para análise a partir dos critérios de Redes Semânticas. Estes dados foram descritos através da técnica de Redes Semânticas, o Núcleo da Rede (NR), Peso Semântico (PS) e Distância Semântica (DS) de ambos os grupos de professores. Obteve-se o Peso Semântico de cada palavra somando as frequências pela hierarquização de importância.

O Núcleo da Rede foi obtido a partir das cinco palavras com maior peso semântico, sendo estas as palavras que melhor definem o conceito. A distância semântica se obteve a partir das palavras definidoras do Núcleo da Rede; a palavra com maior peso recebeu $100 \%$ e as porcentagens das demais se deu por uma regra de três simples.

Os dados coletados por meio das entrevistas foram codificados pela análise de conteúdo temática de Bardin (2011), desta forma, empregou-se a análise de conteúdo temática para analisar as informações obtidas, discriminando as unidades de sentido do texto, ou seja, as principais opiniões, crenças e tendências encontradas nas respostas das entrevistas, através de leitura flutuante, buscando determinar características associadas ao tema central, logo após essas unidades foram agrupadas em categorias de análise para a compreensão das principais representações dos professores quanto às novas tecnologias.

\section{Resultados}

Os resultados obtidos por meio do TALP possibilitaram a análise dos campos de significados derivados das redes semânticas acerca da palavra estímulo aprendizagem (ver Tabela 2).

A partir da análise estrutural das redes semânticas, os elementos da representação compartilhados pelo grupo de professores da escola que possuía robótica educacional em sua grade curricular frente a palavra estímulo "aprendizagem", concentraram em seus núcleos centrais termos como: educação (100\%), didática (58.6\%), ensino (52\%), e contato (60\%) enquanto que os elementos periféricos centraram-se em socialização (6.6\%). No grupo de professores da escola que não possuía a robótica educacional em sua grade curricular, os termos prontamente eliciados frente a palavra estímulo aprendizagem foram: dedicação (100\%), saber (68.5\%), educação (34.3\%), conhecimento (25.7\%) e uma menor frequência para o termo esforço (8.6\%).

Nos resultados obtidos através da análise de conteúdo por meio de leitura flutuante da entrevista semiestruturada, obteve-se a categoria temática aprendizagem que resultou em três subcategorias relacionadas às representações dos professores, são elas: processo de ação contínua com enfoque no cotidiano, transmissão e absorção de conhecimento e estimulação através da interação mediada (ver Tabela 3).

Actualidades en Psicología, 34(129), 2020, 33-45 
Tabela 2

Rede semântica do estímulo "aprendizagem"

\begin{tabular}{|c|c|c|c|c|c|}
\hline \multicolumn{3}{|c|}{ Possuíam robótica educacional } & \multicolumn{3}{|c|}{ Não possuíam robótica educacional } \\
\hline NR & PS & DSQ\% & NR & PS & DSQ\% \\
\hline Educação & 65 & 100 & Dedicação & 45 & 100 \\
\hline Didática & 45 & 9.2 & Saber & 42 & 93.3 \\
\hline Ensino & 30 & 66.6 & Educação & 38 & 90.4 \\
\hline Contato & 18 & 60 & Conhecimiento & 14 & 36.8 \\
\hline
\end{tabular}

Nota. $N R=$ Núcleo da rede; $P S=$ Peso semântico; $D S Q=$ Distância semântica quantitativa.

Tabela 3

Categorização da análise de conteúdo temática

\begin{tabular}{|c|c|c|c|c|}
\hline \multirow[b]{2}{*}{ Subcategorias } & \multicolumn{2}{|c|}{$\begin{array}{l}\text { Possuíam robótica } \\
\text { educacional }\end{array}$} & \multicolumn{2}{|c|}{$\begin{array}{c}\text { Não possuíam robótica } \\
\text { educacional }\end{array}$} \\
\hline & $\mathrm{F}$ & $\%$ & $F$ & $\%$ \\
\hline $\begin{array}{l}\text { Processo de ação contínua } \\
\text { com enfoque no cotidiano }\end{array}$ & 16 & 51.6 & 9 & 30 \\
\hline $\begin{array}{l}\text { Transmissão e absorção } \\
\text { de conhecimento }\end{array}$ & 1 & 3.2 & 12 & 40 \\
\hline $\begin{array}{l}\text { Estimulação através da } \\
\text { interação mediada }\end{array}$ & 14 & 45.1 & 9 & 30 \\
\hline Total & 31 & 100 & 30 & 100 \\
\hline
\end{tabular}

Nota. Subcategorias das análises das entrevistas dos dois grupos de professores participantes do estudo.

\section{Aprendizagem como processo de ação contínua com enfoque no cotidiano}

O grupo de professores da escola que possuíam robótica educacional na grade curricular nessa subcategoria, quando em comparação com o grupo de professores que não possuíam, eliciaram em suas falas na entrevista, numa frequência de 16 vezes, que a aprendizagem "é um processo de criar, transformar, de acordo com as informações que estão aí dispostas na sociedade, isso dá até mais motivação para o aluno nesse aprender" - professora, 42 anos, licenciada em História. Enquanto os professores que não possuíam eliciaram 9 vezes afirmando que, "na contemporaneidade, a naturalização do convívio da tecnologia com a educação torna necessária a mudança do repasse do saber, caso contrário, o aluno não escuta e nem aprende" - professor, 34 anos, licenciado em Linguagens.

\section{Aprendizagem como transmissão e absorção de conhecimento}

Nesta subcategoria, o grupo de professores que possuíam a robótica educacional, apresentou apenas uma vez em suas falas ao caracterizar a aprendizagem como "um processo de aprender algo novo de acordo com as informações disponibilizadas em 
sala de aula ou ao redor do mundo em que se vive" - professora, 35 anos, licenciada em Pedagogia. Já os professores que não possuíam robótica educacional em sua grade curricular, apresentaram 12 vezes em seus discursos a aprendizagem como "um acúmulo de conhecimentos que é transmitido por meio de um conjunto de técnicas desenvolvidas para atingir um alvo que é o acesso e absorção do conhecimento" - professor, 49 anos, licenciado em Geografia.

\section{Aprendizagem como estimulação através da interação mediada}

Nesta subcategoriao grupo de professores que possuía robótica educacional em sua grade curricular apresenta uma frequência de 14 vezes a aprendizagem como "aprender algo novo de diferentes formas de forma compartilhada e vivida" professora, 29 anos, licenciada em Letras-Inglês. Os professores que não possuíam a robótica educacional em seu contexto apresentaram uma frequência de 9 vezes a aprendizagem enquanto "efeito da transmissão de conhecimento em que o aluno tem que participar e prestar bastante atenção para no final ter como resultado a geração de um novo conhecimento". - professora, 25 anos, licenciada em Química.

\section{Discussão}

Aprendizagem é provavelmente um dos termos mais usados no contexto da educação, mas também um dos termos com maior dificuldade de definição. Aprende-se algo quando o processo cognitivo ocorre no cérebro dos indivíduos, quando eles assimilam conhecimento, ou seja, um processo que abrange a interconexão entre conteúdo, método e resultados (Chaib, 2003).

As teorias da aprendizagem contemplam diferentes visões sobre o processo de aprender. Segundo Scheller et al. (2014) a visão de Seymour Papert define aprendizagem é aquilo que ocorre em um contexto de descobertas, de experiências e novos contatos motivados pelo diálogo, em um ambiente propício.; éalgo resultante da interação do sujeito com o objeto do conhecimento, que não se reduz ao objeto concreto, mas inclui o outro, a família, a escola, o social (Scheller et al., 2014).

É vista como um processo de comunicação no qual relacionamentos grupais e interações individuais desempenham um papel decisivo em relação àquilo que deve ser aprendido. Não pode ser definida claramente, a menos que faça referência às diversas situações e condições nas quais o aprendizado se dá (Chaib, 2003). Em ambientes de criação proporcionados pela robótica educacional, o professor torna-se um orientador com o papel de auxiliar o aluno na busca por respostas através de problematizações (Cruz, 2008; Gregio, 2004).

No presente estudo, o grupo de professores que possuía a robótica educacional em seu contexto, atribuiu em seus núcleos de rede a aprendizagem enquanto educação, didática, ensino, contato e socialização elementos que corroboram com princípios básicos da teoria da aprendizagem construcionista, desenvolvida por Papert. Baseada na Teoria Construtivista de Jean Piaget, ela vê a aprendizagem como um processo resultante da autonomia do aluno no processo de construção do conhecimento (Santos \& Lima, 2018 ).

Enquanto o grupo de professores que não a possuía em sua grade curricular, ele atribuiu em seus núcleos de rede à aprendizagem representações desta com um caráter de busca daquele que aprende, ou seja, a aprendizagem só é possível se houver a presença de dedicação, saber, educação, conhecimento e esforço. A abordagem estrutural das representações sociais salienta que um grupo social elabora e/ou assimila ideias, crenças

Actualidades en Psicología, 34(129), 2020, 33-45 
e imagens acerca do mundo, da realidade, em função do lugar que ocupa na sociedade e que o núcleo central está ligado a sua história coletiva, constituído de elementos com significações históricas (do Amaral \& Silva, 2013).

Essa abordagem trata das representações sociais como estruturas de conhecimento sobre temas da vida social, compartilhadas por grupos e formadas por elementos cognitivos ligados entre si (Wachelke \& Wolter, 2011). Uma representação social se constitui como um conjunto organizado e estruturado de informações, crenças, opiniões e atitudes, composta de dois subsistemas denominados de núcleo central e o periférico, onde cada um tem um papel específico e complementar (Abric, 1998). O núcleo central é composto pelos elementos estáveis ou mais permanentes da representação social, sendo estes de natureza normativa e funcional. Os aspectos funcionais estão ligados à natureza do objeto representado e os normativos dizem respeito aos valores e normas sociais pertencentes ao meio social do grupo. Já o sistema periférico é complemento indispensável do central, uma vez que protege esse núcleo, atualiza e contextualiza constantemente suas determinações normativas, permitindo uma diferenciação em função das experiências cotidianas nas quais os indivíduos estão imersos (Machado \& Aniceto, 2010).

A representação de um grupo social demonstra as faces de sua realidade, permite compreender os aspectos sociais, políticos, econômicos e culturais, nos quais ele está inserido (Silva \& Lima, 2013). É notável, nos núcleos de rede de ambos os grupos, que os termos representativos apresentam abordagens para práticas pedagógicas distintas, uma vez que os acercamentos de suas representações são termos característicos de teorias da aprendizagem com abordagens distintas, como o instrucionismo e construcionismo (Alvarenga, 2018). Conhecer as representações de um grupo oferece a compreensão de como os sujeitos sociais apreendem os acontecimentos da vida diária, as características do meio, as informações que circulam e as relações sociais (Silva \& Silva, 2017).

Diante dos discursos analisados nas entrevistas, observou-se que os professores do grupo que não possuía robótica educacional representaram em suas falas com maior frequência a aprendizagem atrelada ao ato de transmitir e absorver conhecimento (Verdum, 2013) e tal expressão se contrapõe à concepção da escola como um local de construção do conhecimento e de socialização do saber (MEC \& SEF, 1998).

É conferida a escola a missão de socializar, na perspectiva de colaborar, para que os alunos aprendam a aprender na convivência com os outros, desenvolvendo nestes uma postura construtiva e participativa (MEC \& SEF, 1998), cabendo ao professor a função de levar o aprendizado de um modo especial observando que a metodologia utilizada no processo de construção de conhecimento faz toda diferença (Mel et al., 2015).

A visão da aprendizagem enquanto transmissão e absorção relaciona-se com a perspectiva interacionista que consiste em programar informações para repassar aos alunos como um tutorial. O ensino instrucionista tem suas raízes nos métodos tradicionais de ensino (Silva et al., 2015). Essa abordagem também contribui para a aquisição da aprendizagem do aluno, no entanto, as práticas pedagógicas diferem da proposta construcionista (Alvarenga, 2018).

Nesse sentido, o aprender dos alunos depende não somente dos seus esforços, mas também da construção de práticas, currículos e metodologias que correspondam aos paradigmas seguidos na educação atual (Silva \& Lima, 2013). O que vai de encontro ao núcleo de rede eliciado por professores da escola que não possuía robótica educacional ao elucidar aprendizagem enquanto esforço. 
Compreender a aprendizagem como um processo de ação contínua com enfoque no cotidiano e estimulação pela interação mediada implica considerar que a aprendizagem deixa de ser algo passivo para tornar-se uma obra de reconstrução permanente, dinâmica entre sujeitos que se influenciam mutuamente (Cruz, 2008), ou seja, resulta da interação do sujeito com o objeto do conhecimento (Chitolina et al., 2016), o processo de ensino e aprendizagem se dá na interação (Silva \& Silva, 2017).

Desta forma, deriva-se daí a necessidade de apreensão das representações sociais acerca da aprendizagem, por compreendê-las como conjuntos dinâmicos que produzem comportamentos e relacionamentos com o meio ambiente que se modificam na relação entre sujeitos e que permite compreender também aspectos sociais (Silva \& Lima, 2013) em que se inserem estes professores, uma vez que fazem parte de cenários escolares diferentes, mas de contextos sociais que se assemelham e que o contexto tecnológico atual provoca mudanças nas práticas pedagógicas dos professores o que por consequência molda sua forma de ensinar e do aluno aprender (Alvarenga, 2018).

O estudo teve como objetivo apreender representações sociais dos professores sobre a aprendizagem, que possuíam ou não robótica educacional na grade curricular do seu contexto escolar, comparando suas representações em sua aproximação com a tecnologia robótica educacional. Sobre núcleos de rede derivados da análise semântica, salienta-se que nas representações sociais de aprendizagem do grupo que não possuía robótica educacional na grade curricular prevaleceram os elementos dedicação, saber, educação, conhecimento e esforço. Sob uma perspectiva mais construcionista, o grupo que possuía robótica educacional em sua grade curricular apresentou elementos como educação, didática, ensino, contato e socialização.

Nos resultados obtidos da análise de conteúdo, observou-se que o grupo que não possuía robótica educacional quando em comparação com o grupo que possuía robótica, apesar de expressar em seus núcleos de rede representações não tão distantes, elucidou em seu discurso a aprendizagem como um processo baseado em instruções, em que o aluno recebe um saber transmitido. E o grupo que possuía robótica elucidou com maior frequência a aprendizagem como um processo baseado na interação e construção.

Os núcleos de rede dos dois grupos de professores e seus discursos apresentam termos representativos das abordagens instrucionista e construcionista, teorias da aprendizagem que orientam as práticas pedagógicas no processo de ensino e aprendizagem. Tais representações chamam atenção para a teoria da aprendizagem adotada no contexto escolar. No entanto, como lacuna do estudo, não foram analisadas as práticas pedagógicas proporcionadas pelos ambientes de aprendizagem pesquisados. Espera-se que estudos futuros investiguem a influência das representações sociais de professores inseridos no contexto tecnológico atual, de grupos de pertença diferentes, observando suas práticas pedagógicas no cotidiano escolar.

\section{Referências}

Abric, J. (1998). A abordagem estrutural das representações sociais. En A. Moreira \& D. Oliveira (Orgs.). Estudos interdisciplinares de representação social (pp. 27-38). AB Editora.

Alvarenga, C. (2018). Práticas pedagógicas com recursos digitais: instrucionistas ou construtivistas? Informática na educação: teoria \& prática, 21(3), 10-37. https:// doi.org/10.22456/1982-1654.71743

Actualidades en Psicología, 34(129), 2020, 33-45 
Bardin, L. (2011). Análise de conteúdo. Edições 70.

Barros, A., Coutinho, M., Araújo, L., \& Castanha, A. (2006). As representações sociais da depressão em adolescentes no contexto do ensino médio. Estudos de Psicologia, 23(1), 19-28. https://doi.org/10.1590/S0103-166X2006000100003

Castro, R. (2007). Das formas de ensinar e de aprender e os desafios do século XXI. ETD - Educação Temática Digital, 9(1), 115-123. https://doi.org/10.20396/etd.v9i1.742

Chaib, C. (2003). De professor comum a nerd informático. Nuances: estudos sobre educação, 9(9/10), 11-45. https://doi.org/10.14572/nuances.v9i9/10.395

Chitolina, R., Noronha, F., \& Backes, L. (2016). A Robótica Educacional como tecnologia potencializadora da aprendizagem: das ciências da natureza às ciências da computação. Educação, Formação \& Tecnologias, 9(2), 56-65. https://eft.educom. pt/index.php/eft/article/view/538/258

Coutinho, C., \& Lisbôa, E. (2011). Sociedade da informação, do conhecimento e da aprendizagem: desafios para educação no século XXI. Revista de Educação, 13(1), 5-22. http://revista.educ.ie.ulisboa.pt/arquivo/vol_XVIII_1/artigo1.pdf

Cruz, J. (2008). Processo de ensino-aprendizagem na sociedade da informação. Educação \& Sociedade, 29(105), 1023-1042. https://doi.org/10.1590/S010173302008000400005

do Amaral, L., \& Alves, M. (2013). Nó ou Núcleo central e esquema periférico. Cadernos Cespuc Pesquisa Série Ensaios. 1(23), 30-36. http://periodicos.pucminas.br/index. php/cadernoscespuc/article/view/8300

França, C., \& Simon, B. (2013). O Uso das Tecnologias no Ensino e no Ensino de História: Abordagem Construcionista ou Instrucionista. UNOPAR Científica. Ciências Humanas e Educaçao, 14(3), 207-216. https://revista.pgsskroton.com/index.php/ ensino/article/download/615/582

Gregio, B. (2004). A informática na educação: as representações sociais e o grande desafio do professor frente ao novo paradigma educacional. Revista Digital da CVA - Ricesu, 2(6).

Gurgel, C. R., de Aguiar, G. E., \& Silva, N. N. (2013). Avaliação como espaço de aprendizagem em softwares educativos. Ensaio: Avaliação e Políticas Públicas em Educação, 27(79), 371-388. https://dx.doi.org/10.1590/S0104-40362013000200010

Instituto Brasileiro de Geografia e Estatística. (2010). Panorama populacional. Censo demográfico, 2010. https://cidades.ibge.gov.br/brasil/pi/parnaiba/panorama

Machado, L., \& Aniceto, R. (2010). Núcleo central e periferia das representações sociais de ciclos de aprendizagem entre professores. Ensaio: Avaliação e Políticas Públicas em Educação, 18(67), 345-364. https://doi.org/10.1590/S0104-40362010000200009

Ministério da Educação e do Desporto \& Secretaria de Educação Fundamental. (1998). Parâmetros curriculares nacionais. Ciências Naturais. Ministério da Educação e do Desporto \& Secretaria de Educação Fundamental. http://portal.mec.gov.br/ seb/arquivos/pdf/ciencias.pdf

Moreira, L., Cavalcante, F., \& Meireles, A. (2014). Tecnologias educacionais: um cenário para uma prática pedagógica inovadora. Revista Expressão Católica, 3(1), 319-36.

Actualidades en Psicología, 34(129), 2020, 33-45 
Mel, L., Danelussi, D., Filho, A., Loose, J., \& Anjos, Q. (2015). Os Desafios dos Educadores do Século XXI: Ensinar Com Alegria e Criatividade. Revista Saberes, Rolim de Moura, 3(2), 126-137. https://facsaopaulo.edu.br/wp-content/uploads/sites/16/2018/05/ ed3/11.pdf

Quinaud, A., \& Baldessar, M. (2017). A educação no século XXI: gamificação aprendizagem com criatividade. Temática, 13(11), 215-228. https://doi.org/10.22478/ufpb.18078931.2017v13n11.37267

Santos, J. T., \& de Lima, J. S. (2018). Robótica Educacional e Construcionismo como proposta metodológica para o desenvolvimento de ambientes de aprendizagem significativa. RENOTE-Revista Novas Tecnologias na Educação, 16(2), 596-605. https://doi.org/10.22456/1679-1916.89300

Scheller, M., Viali, L., \& Lahm, R. A. (2014). A Aprendizagem no contexto das tecnologias: uma reflexão para os dias atuais. RENOTE-Revista Novas Tecnologias na Educação, 12(2). https://doi.org/10.22456/1679-1916.53513

Silva, A., \& Lima, C. (2013). O uso do computador no processo de ensino e aprendizagem: questões de representação social. Revista Linhas, Florianópolis, 14(27), 158-178. http://dx.doi.org/10.5965/1984723814272013158

Silva, I., Prates, T., \& Ribeiro, L. (2016) As Novas Tecnologias e aprendizagem: desafios enfrentados pelo professor na sala de aula. Revista Em Debate (UFSC), Florianópolis, 16, 107-123. https://doi.org/10.5007/1980-3532.2016n15p107

Silva, R., \& Correa, E. (2014). Novas tecnologias e educação: a evolução do processo de ensino e aprendizagem na socieade contemporânea. Educação \& Linguagem, 7(1), 23-35. https://www.fvj.br/revista/wp-content/uploads/2014/12/2Artigo1.pdf

Silva, V., \& Silva, C. (2017). O desafio da educação no início do século xxi: as novas tecnologias como facilitadoras da aprendizagem. Revista de Pós-Graduação Multidisciplinar, São Paulo, 1(2), 159-173.

Silva, W., Kalhil, J., \& Nicot, Y. (2015). Uma análise comparativa das abordagens metodológicas que podem sustentar a utilização das tecnologias no processo de ensino e aprendizagem de ciências. Revista REAMEC, 03(1), 5-24. http://dx.doi. org/10.26571/2318-6674.a2015.v3.n1.p5-24.i5303

Vargas, R. (2003). Escala de actitudes hacia la tecnología en el aprendizaje escolar aplicada a niños y niñas de primaria pública en Costa Rica. Análisis de validez y confiabilidad. Actualidades en Psicología, 19(106), 24-45. https://doi.org/10.15517/ ap.v19i106.45

Vera-Noriega, J. (2005). Redes Semánticas: Método y Resultados. In A.S.P. Moreira, B.V. Camargo, J.C. Jesuíno \& S.M. Nóbrega (Orgs.). Perspectivas Teórico Metodológicas em Representações Sociais (pp. 489-510). Editora UFPB.

Verdum, P. (2013). Prática Pedagógica: o que é? O que envolve? Revista Educação por Escrito - PUCRS, 4(1). http://revistaseletronicas.pucrs.br/ojs/index.php/porescrito/ article/view/14376/9703

Wachelke, J., \& Wolter, R. (2011). Critérios de construção e relato da análise prototípica para representações sociais. Psicologia: Teoria e Pesquisa, 27(4), 521-526. https:// doi.org/10.1590/S0102-37722011000400017 
Zambon, M., Souza., \& Rose, T. (2012). Autoeficácia e experiência de professores no uso de tecnologias de informática. Revista Brasileira de Informática na Educação, Florianópolis, 20(2), 44-53. http://dx.doi.org/10.5753/rbie.2012.20.2.44

Actualidades en Psicología, 34(129), 2020, 33-45 